Distribution of asthma and lung function in participants aged 42 according to severity of asthma at age 7 or 10

\begin{tabular}{|c|c|c|c|c|c|c|c|c|}
\hline \multirow[b]{2}{*}{ Symptoms age 7} & \multicolumn{5}{|c|}{ No (\%) at age 42} & \multicolumn{3}{|c|}{ Lung function at age 42} \\
\hline & $\begin{array}{c}\text { No recent } \\
\text { asthma }(n=199)\end{array}$ & $\begin{array}{c}\text { Infrequent } \\
\text { asthma }(n=58)\end{array}$ & $\begin{array}{l}\text { Frequent asthma } \\
\qquad(\mathrm{n}=76)\end{array}$ & $\begin{array}{c}\text { Persistent } \\
\text { asthma }(n=70)\end{array}$ & $\begin{array}{c}\text { Total } \\
(\mathrm{n}=403)\end{array}$ & $\begin{array}{c}\text { No measured } \\
(n=267)\end{array}$ & $\begin{array}{l}\mathrm{FEV}_{1} / \mathrm{FVC} \\
(95 \% \mathrm{Cl})\end{array}$ & $\begin{array}{c}\text { Mean \% of } \\
\text { predicted } \mathrm{FEV} \\
(95 \% \mathrm{Cl})\end{array}$ \\
\hline Mild wheezy bronchitis & $40(66)$ & $12(20)$ & $9(15)$ & 0 & 61 & 40 & 80 (79 to 82$)$ & $109(103$ to 114$)$ \\
\hline Wheezy bronchitis & $50(57)$ & $13(15)$ & $16(18)$ & $9(10)$ & 88 & 62 & 79 (76 to 81) & 102 (98 to 106) \\
\hline Asthma & $28(29)$ & $19(19)$ & $27(28)$ & $24(24)$ & 98 & 70 & $75^{\star}$ (73 to 77 ) & $95^{*}$ (92 to 99$)$ \\
\hline Severe asthma & $8(11)$ & $9(13)$ & $20(29)$ & $33(47)$ & 70 & 42 & $70^{\star}(67$ to 74$)$ & $85^{\star}$ (78 to 91$)$ \\
\hline Control & $73(85)$ & $5(6)$ & $4(5)$ & $4(5)$ & 86 & 53 & 80 (78 to 82$)$ & 104 (101 to 108) \\
\hline
\end{tabular}

$\mathrm{FEV}_{1}=$ forced expiratory volume in 1 second; $\mathrm{FVC}=$ forced vital capacity.

${ }^{*} \mathrm{P}<0.001$ compared with controls

Fifteen of the original cohort had died at follow up, one from asthma. Of the remaining 464, 403 participated in the current review, giving a continuing participation rate of $87 \%$. In all, 267 participants attended the laboratory for measurement of lung function. We calculated mean values of lung function using standard two sample $t$ tests and confidence intervals of the mean by standard methods.

The table shows the clinical expression of asthma at age 42 according to severity of disease at recruitment. The distribution of severity at age 42 has not changed from that at age $35 .{ }^{5}$ The proportion of cases with no recent asthma has increased steadily from $20 \%$ at age 14 years to $40 \%(126 / 317)$ at age 42 .

Lung function was similar to that of controls in participants who had had wheezy bronchitis in childhood (table). Participants who had had asthma aged 7 had reduced lung function at age 42 .

\section{Comment}

Our study shows that the pattern of asthma during childhood predicts outcome. Most children with persistent asthma had continuing symptoms into adult life and reduced lung function. However, children who had intermittent symptoms associated with respiratory tract infections generally had complete resolution of symptoms in adult life. The small number of participants who still had mild, intermittent symptoms at age 42 had normal lung function. This good outcome was achieved despite the fact that anti-inflammatory treatments were not available for most of their childhood.

Contributors: CFR, AO, and JW initiated the project and, together with $\mathrm{EH}, \mathrm{AL}, \mathrm{MR}$ and $\mathrm{LW}$, developed the protocol. EH, AL, MR, and LW were responsible for recruitment, data collection, and data analysis. JBC was the statistician. The manuscript was jointly written and reviewed by all of the authors. CFR is the guarantor.

Funding: National Health and Medical Research Council of Australia. EH was funded by Nationalbank, Austria.

Competing interests: None declared.

1 Ahmed IH, Samet JM. The natural history of asthma. In: Murphy S, Kelly HW, eds. Pediatric asthma. Vol 126. New York: Marcel Dekker, 1999:41-69.

2 Williams HE, McNichol KN. Prevalence, natural history and relationship of wheezy bronchitis and asthma in children: an epidemiological study. BMJ 1969;iv:321-5.

3 McNichol KN, Williams HB. Spectrum of asthma in children. I. Clinical and physiological components. BMJ 1973;iv:7-11.

Kelly WJ, Hudson I, Phelan PD, Pain MC, Olinsky A. Childhood asthma in adult life: a further study at 28 years of age. BMJ 1987;294:1059-62.

5 Oswald H, Phelan PD, Lanigan A, Hibbert M, Bowes G, Olinsky A. Outcome of childhood asthma in mid-adult life. BMJ 1994;309:95-6.

(Accepted 7 November 2002)

\title{
Spontaneous loss of early pregnancy and risk of ischaemic heart disease in later life: retrospective cohort study
}

\author{
Gordon C S Smith, Jill P Pell, David Walsh
}

We recently showed that complications in late pregnancy are associated with an increased risk of maternal ischaemic heart disease (IHD) in later life. ${ }^{1}$ We hypothesised that this may reflect common determinants, such as thrombophilic genetic defects and anticardiolipin antibodies. Spontaneous losses of pregnancy are also associated with inherited and acquired thrombophilias in the mother. ${ }^{2}$ We examined whether spontaneous losses of early pregnancy are associated with maternal risk of IHD.

\section{Participants, methods, and results}

We used routine national maternity data (SMR2) to identify all 129290 eligible women who delivered their first liveborn infant in Scotland during 1981-5. The exclusion and inclusion criteria, definitions, and demographic characteristics were as previously described. ${ }^{1}$ We used national death (GRO) and discharge (SMR1) data to determine the risk of death or hospital admission due to IHD during 1981-99. The cumulative probabilities of survival free from IHD events were assessed with Cox's proportional hazards models with age as the time scale (Stata version 7.0, StataCorp, College Station, TX,USA).

A history of any spontaneous loss of early pregnancy before the first live birth was associated with an increased risk of IHD (table). The association was independent of maternal age at the time of first birth, height, socioeconomic deprivation, essential hypertension, and complications during the first pregnancy. The magnitude of the risk increased with the number of previous losses. By contrast, there was no association between therapeutic abortion and subsequent risk of IHD (adjusted hazard ratio $0.93,95 \%$ confidence interval 0.59 to 1.46 ). Only $0.1 \%$ (162) of women had had a hernia repair, and there was no significant association

\section{Clinical}

Epidemiology and Biostatistics Unit, Murdoch Childrens Research Institute, Parkville 3052, Australia

John B Carlin deputy director

Department of Respiratory Medicine, Alfred Hospital, Melbourne,

Australia

John Wilson associate professor Correspondence to: C F Robertson colin.robertson@ rch.org.au
Department of Obstetrics and Gynaecology, Cambridge University, Box 223

The Rosie Hospital,

Cambridge

CB2 2QQ

Gordon C S Smith professor

Department of Public Health, Greater Glasgow Health Board, Dalian House,

Glasgow G3 8YU

Jill P Pell consultant Information and Statistics Division, Common Services Agency, Edinburgh EH5 3SE

David Walsh statistician

Correspondence to: G C S Smith gcss2@cam.ac.uk

BMJ 2003;326:423-4 
Maternal ischaemic heart disease events and number of previous spontaneous losses of early pregnancy losses. Figures are hazard ratios $\left(95 \%\right.$ confidence interval) ${ }^{\star}$

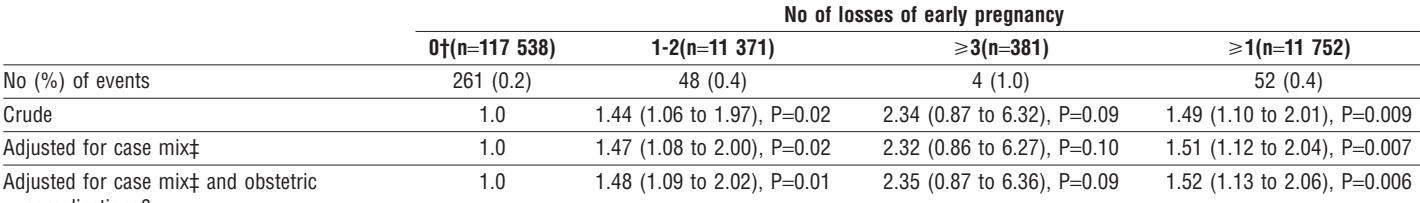
complications§

*All covariates in multivariate models were significantly associated with ischaemic heart disease. Proportional hazard assumption tested with Stata "stphtest" command with Schoenfeld residuals. There was no evidence for violation of assumption in any model (all $P>0.5)$.

†Reference category.

$\ddagger$ Age, height, deprivation, and essential hypertension in first pregnancy.

$\S$ Lowest fifth of birthweight distribution, preterm delivery, pre-eclampsia.

with spontaneous early pregnancy loss $(0.93,0.55$ to 1.59), suggesting that there was no bias due to selective migration. We did not have data on the smoking status of women in the 1981-5 cohort. However, we had data on 181636 women who had a first livebirth from 1992 to 1998 , inclusive. The proportion of women who were current smokers at the first attendance for prenatal care was only marginally higher among women with a history of spontaneous loss of early pregnancy (28.4\%) than among those with no such history $(26.8 \%)$.

\section{Comment}

To our knowledge, this is the first study to show a specific association between spontaneous abortion and maternal risk of IHD. Our findings may explain the results of previous studies that have found an association between the total number of pregnancies and maternal risk of IHD as women who suffer recurrent losses of early pregnancy must have more pregnancies to achieve their target family size. ${ }^{3}$ However, it is unlikely that the association between spontaneous abortion and maternal IHD is simply an effect of parity as there was no association with therapeutic abortion.

The strengths of our study are that prospective data collection precluded bias and, in contrast with a case-control study, we were able to include women who subsequently died. However, further studies are required to corroborate our findings and to confirm that the association is independent of smoking and other confounding factors, such as maternal disease (for example, diabetes and polycystic ovarian syndrome).
Several studies have shown associations between acquired and inherited thrombophilias and both spontaneous loss of early pregnancy ${ }^{2}$ and IHD. ${ }^{4}$ Implantation of the embryo and development of the placenta involve complex adaptations of the mother's cardiovascular and microvascular systems. We hypothesise that occult cardiovascular, microvascular, or haemostatic dysfunction result in pregnancy complications during reproductive years and in overt cardiovascular disease in later life. A woman's reproductive history may, therefore, inform future cardiovascular risk.

Contributors: GCSS had the original concept, reviewed previous publications, undertook the statistical analyses, and is guarantor. GCSS and JPP wrote the initial draft. DW performed the record linkage. GCSS, JPP, and DW agreed the study design, interpreted the results, revised the original draft, and approved the final version.

Competing interests: None declared.

Funding: Chief Scientist Office, Scottish Executive Health Department (CZG/4/2/22).

1 Smith GCS, Pell JP, Walsh D. Pregnancy complications and maternal risk of ischaemic heart disease: a retrospective cohort study of 129290 births. Lancet 2001:357:2002-6.

2 Souza SS, Ferriani RA, Pontes AG, Zago MA, Franco RF. Factor V Leiden and factor II G20210A mutations in patients with recurrent abortion. Hum Reprod 1999;14:2448-50

3 Ness RB, Harris T, Cobb J, Flegal KM, Kelsey JL, Balanger A, et al. Number of pregnancies and the subsequent risk of cardiovascular disease. N Engl J Med 1993;328:1528-33.

4 Rosendaal FR, Siscovick DS, Schwartz SM, Beverly RK, Psaty BM, Longstreth WT Jr, et al. Factor V Leiden (resistance to activated protein C) increases the risk of myocardial infarction in young women. Blood C) increases the risk

5 Vaarala O. Antiphospholipid antibodies and myocardial infarction. Lupus 1998;7(suppl 2):S132-4.

(Accepted 12 December 2002)
Erectile dysfunction, the consistent inability to achieve or maintain an erection sufficient for satisfactory sexual performance, is reported to occur in association with cardiovascular disease, diabetes, hypertension, hypercholesterolaemia, smoking, spinal cord injury, prostate cancer, genitourinary surgery, psychiatric disorders, and the use of many drugs, including alcohol. ${ }^{1}$ Sildenafil (Viagra), an oral treatment for erec- 